\title{
Mental capacity to consent to treatment in anorexia nervosa: explorative study
}

\author{
Isis F. F. M. Elzakkers, Unna N. Danner, Hans W. Hoek and Annemarie A. van Elburg
}

\section{Background}

Mental capacity to consent to treatment in anorexia nervosa is a neglected area in clinical decision-making.

\section{Aims}

To examine clinical and neuropsychological parameters associated with diminished mental capacity in anorexia nervosa.

\section{Method}

An explorative study was conducted in 70 adult female patients with severe anorexia nervosa. Mental capacity to consent to treatment was assessed by experienced psychiatrists. Further measurements included the MacCAT-T (to assess mental capacity status), a range of clinical measures (body mass index (BMI) and comorbidity) and neuropsychological tests assessing decision-making, central coherence and set-shifting capacity.

\section{Results}

Diminished mental capacity occurs in a third of patients with severe anorexia nervosa and is associated with a low BMI, less appreciation of illness and treatment, previous treatment for anorexia nervosa, low social functioning and poor set shifting.

\section{Conclusions}

Assessment of diminished mental capacity in anorexia nervosa requires careful evaluation of not only BMI, but also the degree of appreciation of illness and treatment, history and the tendency to have a rigid thinking style.

\section{Declaration of interest}

None.

\section{Copyright and usage}

(C) The Royal College of Psychiatrists 2016. This is an open access article distributed under the terms of the Creative Commons Non-Commercial, No Derivatives (CC BY-NC-ND) licence.
Anorexia nervosa is a severe mental disorder with a high mortality rate. ${ }^{1}$ The crude mortality rate is $5.1 \%$ per decade, the standardised mortality ratio is $5.86 .^{2}$ Prognosis is not favourable, with complete recovery rates of only $50 \%$ in an adult population; around $30 \%$ of patients have a partial recovery and $20 \%$ remain severely ill. ${ }^{3}$ The lifetime prevalence among young females ranges between 0.3 and $2.4 \%{ }^{4}$ Anorexia nervosa typically afflicts adolescent women and has a mean duration of illness to recovery of 7 years. ${ }^{5}$ The causes of anorexia are not yet fully elucidated, but appear to be multifactorial, with determinants including genetic and neurobiological influences and pressures in the environment with respect to appearance. ${ }^{6,7}$

Despite the obvious severity of the disorder, many patients are reluctant to engage in treatment, especially if treatment entails a focus on increased food intake and weight gain. This may partly explain why only a minority of individuals with anorexia nervosa are treated within the mental healthcare system. ${ }^{1}$ To patients with anorexia, food does not have the same reward value as it does to healthy people. Various mechanisms have been put forward as potential contributors to this phenomenon. ${ }^{7}$ For example, altered reward processing seems to play a role in the heightened saliency of not eating by modulating emotional distress. ${ }^{8}$ In the later stages this behaviour becomes habitual and thereby refractory to change, a process even further enhanced by the increased compulsivity observed in underweight individuals. ${ }^{9}$ Neuropsychological difficulties like inefficient set-shifting, poor central coherence and impaired decision-making ${ }^{10-15}$ can complicate treatment because of a difficulty to change set behaviour and a bias towards focusing on details (e.g. the present meal and its dreaded consequences) instead of the future benefits of being able to function again in daily life. Finally, the finding by Tan et $a l^{16}$ that anorexia nervosa becomes part of the personal identity of the patient and that values regarding life and death in the acute phase of the illness differ compared with the remission phase also explains part of the persistence of symptoms. In the light of these clinical and (neuro) psychological findings the question whether or not patients with anorexia are capable of adequate decision-making regarding treatment should be raised. Clinically, this decision-making regarding treatment is referred to as mental capacity. Mental capacity is a task-specific phenomenon and refers to the ability of a patient to adequately process the information provided by the clinician to arrive at an informed decision regarding the medical issue at hand. These issues generally pertain consent to treatment such as surgery, medication or admission to hospital.

Mental capacity is relevant, as lacking mental capacity to consent to treatment means that treatment refusal may be overridden when it would lead to danger to oneself, as is so often the case in severe anorexia nervosa regarding its severe physical consequences. Mental capacity assessments generally check four abilities (based on the widely used model by Grisso \& Appelbaum ${ }^{17}$ ), namely the ability to express a choice about treatment; the ability to understand information relevant to the treatment decision; the ability to appreciate the significance of that treatment information for one's own situation; and the ability to reason with relevant information so as to engage in a logical process of weighing treatment options. In general psychiatry a number of studies have been conducted to assess the proportion of patients lacking mental capacity to consent to treatment (for a review see Okai et $a l^{18}$ ). These studies indicated that lacking this capacity is common (approximately 29\% of in-patients) whereby psychosis, severity of symptoms, compulsory treatment and treatment refusal were the strongest predictors of lacking capacity to consent to treatment. Unfortunately, neither of these papers include any information on anorexia nervosa. Only two small studies examined mental capacity to consent to treatment in patients with anorexia nervosa. ${ }^{19,20}$ Both studies describe an adolescent population and did not include patients with chronic anorexia, although the issue of mental capacity to consent to treatment is fiercely debated in this group in particular. Additionally, results were inconsistent. In the study by Turrell et $a l^{20}$ reasoning was found to be impaired in patients with 
anorexia compared with healthy controls, but in the study by Tan et $a l^{19}$ patients showed excellent mental capacity to consent to treatment. This latter finding needs to be interpreted with caution as this study was small $(n=10)$ and used a retrospective design, not assessing mental capacity at the clinically relevant 'moment'.

Mental capacity assessments used in general medicine tend to focus on cognitive abilities as understanding of the information provided and weighing options. Debate exists whether or not this 'cognitive' approach is able to accommodate the relevance of emotions and values in decision-making. ${ }^{21-23}$ Especially regarding anorexia nervosa, criticism of this cognitive approach to mental capacity has been voiced by some authors. ${ }^{24-26}$ Tan et al have found in previous research ${ }^{19,27}$ that the values regarding life and death of patients who are severely ill change after recovery. The authors refer to the values of the patients as 'pathological' values (i.e. illness driven) and question whether we should give these pathological values the same weight as we would for values regarding life and death of a healthy person. On the other hand it is argued that this concept of values is incorporated in the assessment of the appreciation of the patient regarding disorder and treatment. ${ }^{28}$ This introduces a subjective and morally complex element into the assessment of mental capacity, for who is to decide whether or not values are pathological? The fact that mental capacity is a concept that cannot be measured objectively complicates research into this area. Little is known about mental capacity and the underlying mechanisms of impairment thereof in anorexia. The purpose of this study is to examine which clinical parameters are of importance in the assessment of mental capacity to consent to treatment in anorexia nervosa. Providing more objective data to base mental capacity judgements on is important to support clinicians with this difficult task.

\section{Method}

\section{Study sample}

Altrecht Eating Disorders Rintveld is a specialist eating disorder department of the Altrecht Mental Health Institute that offers assessments, consultation and treatment for in- and out-patients. All consecutive adult female patients who were referred to our centre from February 2012 to July 2013 were eligible for inclusion if they had a diagnosis of anorexia nervosa or eating disorder not otherwise specified clinically referred to as anorexia nervosa according to DSM-IV. ${ }^{29}$ The only exclusion criterion for this study was an IQ lower than 70 , as we expected neuropsychological difficulties in this group of patients related to cognitive impairments. The presence of anorexia nervosa was established by eating disorder experts (all psychiatrists) and confirmed by the Eating Disorder Examination (EDE) ${ }^{30}$ A total of 70 patients were included in the study (Fig. 1); 34 patients refused to participate. Patients who refused to participate did not differ on any of the clinical parameters from the study group (Table 1). The study was conducted in accordance with the ethical standards described by the Medical Research Involving Human Subjects Act (WMO) and was approved by the institutional review board. After complete description of the study to the participants, written informed consent was obtained.

\section{Measures}

\section{Mental capacity}

During the first meeting the psychiatrist examining the patient also assessed mental capacity of the patient relating to the decision to start treatment. This was done in the manner of a general psychiatric interview by enquiring about the patient's beliefs regarding their condition and their ideas about treatment

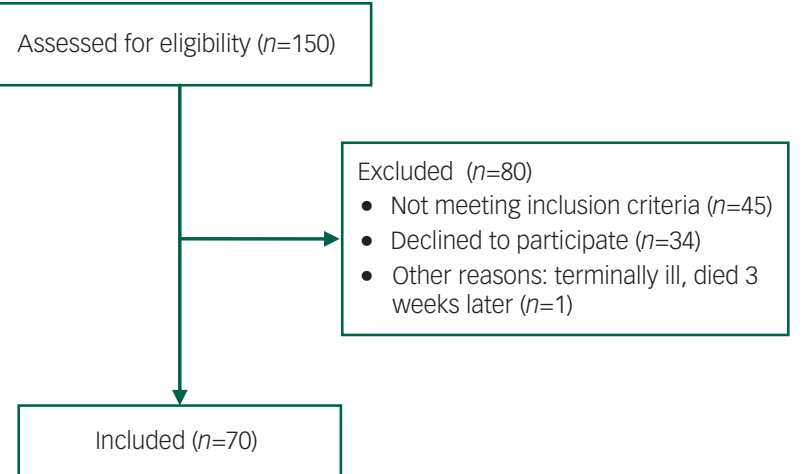

Fig. 1 Flow diagram of inclusion process.

intensity. In this psychiatric assessment attentional function and level of orientation were also routinely assessed to screen for possible delirium. The psychiatrist categorised the outcome of this judgement as full, diminished or lacking mental capacity. The two psychiatrists conducting these examinations were both psychiatrists with several years of experience in specialised eating disorder treatment. They routinely conduct second opinions in complex anorexia nervosa treatments for other centres.

\section{MacCAT-T}

In addition to clinical judgement, we examined the four abilities underlying mental capacity by using the MacArthur Competence Assessment Tool-Treatment (MacCAT-T), ${ }^{31}$ a semi-structured interview to assess mental capacity designed by Grisso \& Appelbaum. The MacCAT-T generates four scores (understanding $0-6$, reasoning $0-8$, appreciation $0-4$ and making a choice $0-2$ ), which should not be combined into a total score. In this way the MacCAT-T provides more insight into particular deficits in a patient's mental capacity. The MacCAT-T was conducted by experienced eating disorder psychiatrists or residents who were trained by the lead investigator and by watching the DVD provided by Grisso \& Appelbaum and reading the manual. ${ }^{17}$ The interview was conducted a week after the first interview with the clinician immediately after the second appointment patients had with the clinician to be advised about the treatment plan. The psychiatrist conducting the MacCAT-T was masked to the mental

\begin{tabular}{|c|c|c|c|}
\hline & $\begin{array}{c}\text { Participants } \\
n=70\end{array}$ & $\begin{array}{l}\text { Non- } \\
\text { participants } \\
n=35\end{array}$ & Significance $^{a}$ \\
\hline Age, years: mean (s.d.) & $27.3(9.7)$ & $26.7(7.7)$ & Ns \\
\hline $\begin{array}{l}\text { Age at onset, years: } \\
\text { mean (s.d.) }\end{array}$ & $17.8(4.9)$ & $17.0(3.6)$ & Ns \\
\hline $\begin{array}{l}\text { Length of illness, years: } \\
\text { mean (s.d.) }\end{array}$ & $8.6(8.1)$ & $10.1(7.9)$ & Ns \\
\hline BMI, mean (s.d.) & $15.5(1.9)$ & $15.4(2.0)$ & NS \\
\hline EDE, mean (s.d.) & $3.6(1.3)$ & $3.4(1.2)$ & Ns \\
\hline ANR, \% & 49 & 40 & NS \\
\hline ANP, \% & 51 & 60 & NS \\
\hline Previous ED treatment, \% & 74 & 80 & NS \\
\hline Previous hospital admission, \% & 46 & 60 & NS \\
\hline Medication, \% & 58 & 46 & Ns \\
\hline History of abuse, \% & 20 & 6 & $P=0.07$ \\
\hline \multicolumn{4}{|c|}{$\begin{array}{l}\text { Ns, not significant; BMl, body mass index; EDE, Eating Disorder Examination; ANR, } \\
\text { anorexia nervosa restrictive type; ANP, anorexia nervosa purging type; ED, eating } \\
\text { disorder. } \\
\text { a. All non-significance levels have a } P \text {-value of } 0.20 \text { or above. }\end{array}$} \\
\hline
\end{tabular}


capacity assessment of the patient by the first psychiatrist (the clinical judgement). The MacCAT-T focused on the treatment advice the patient was given, so it was tailored to their specific situation. Patients generally agreed with the advice given; $92 \%$ did, $8 \%$ did not and received no further treatment in our centre. Recommended treatment could either be in-patient $(47 \%$ of participants) or out-patient (53\%) treatment as our centre deals with patients with different levels of severity and comorbidity. As assessing mental capacity to consent to treatment focuses on the decision-making process and not on specific treatment content or modality, we did not feel the different treatment options recommended would pose a problem to the assessment of mental capacity to consent to treatment.

Interrater reliability testing for the MacCAT-T in this study entailed two independent raters scoring 10 interview forms of the 43 patients who were interviewed by the lead investigator. Intraclass coefficients (ICCs) were calculated and proved good for two subscales (understanding (Cronbach alpha 0.77) and appreciation $(0.87)$ ), but poor for reasoning $(0.30)$. For choice we were unable to calculate ICCs because of very little variance of the raters' scores on this subscale (all raters consistently scored a 2, which is the maximum score, except for one rater who for one patient scored a 1 instead of a 2). The agreement on this subscale therefore was exceptionally high. The low ICC for reasoning is not consistent with other studies. It could be because the raters experienced the scoring of reasoning as more complex than the other subscales. Also, although the ICC is poor, the actual scores on reasoning of the three raters are consistently high (between 6 and 8 , which is the maximum score), so the poor ICC does not reflect large differences in the rating of this subscale.

\section{Clinical measures}

Severity of the eating disorder symptoms was rated with the $\mathrm{EDE}^{30}$ and the body mass index (BMI, in $\mathrm{kg} / \mathrm{m}^{2}$ ) at the first assessment. To assess psychiatric comorbidity the Structured Clinical Interview for DSM-IV (SCID-I) was used. ${ }^{32}$ Earlier, eating disorder treatments and admissions were collected from the psychiatric history and social functioning from the social history. Depression and anxiety levels were measured by using the Beck Depression Inventory (BDI-II) ${ }^{33}$ and Spielberger Stait Trait Anxiety Inventory (STAI). ${ }^{34}$ Furthermore, levels of alexithymia were assessed by using the Toronto Alexithymia Scale (TAS). ${ }^{35,36}$

\section{Neuropsychological measures}

Three tasks were administered: the Iowa Gambling Task (IGT) ${ }^{37}$ was used to assess decision-making ability, the Rey Complex Figure Task (RCFT) ${ }^{38}$ was used to measure strength of central coherence and the Wisconsin Card Sorting Test (WCST) ${ }^{39}$ was used for determining set-shifting ability. All tasks are frequently used to assess neuropsychological functioning in eating disorders. ${ }^{11,13,40}$ These tasks were chosen as in earlier studies ${ }^{11,13,40,41}$ differences were shown between patients with anorexia nervosa and healthy controls, and these differences may be underlying neuropsychological markers associated with mental capacity problems.

\section{Statistical analysis}

Two groups were created: those with full mental capacity and those with diminished or lacking mental capacity. To determine differences between the two groups (full and diminished mental capacity) independent sample $t$-test or $\chi^{2}$ tests were used. To determine interrater reliability of the four subscales of the MacCAT-T, ICCs were calculated. Finally, to examine the association of the IGT with mental capacity, repeated measure ANOVAs were used to test the learning effect between the groups.

\section{Results}

\section{Sample characteristics}

A total of 70 patients participated in the study. Characteristics of participants are shown in Table 2, showing a high illness severity with a low mean BMI, a long duration of illness and a high percentage of previous treatment or hospital admission. The majority of the patients (53\%) had one comorbid Axis I disorder and $31 \%$ had 2 or more comorbid Axis I disorders. Common comorbid disorders were depressive disorder (48.4\%), post-traumatic stress disorder (PTSD; 21.7\%), social anxiety disorder (18.3\%), generalised anxiety disorder (13.3\%), obsessive-compulsive disorder (6.7\%) and panic disorder (6.7\%). None of the patients had delirium. In the Appendix two case vignettes are provided to give a more 'real life' clinical picture of participants.

\section{Mental capacity and associations with clinical parameters}

Diminished mental capacity to consent to treatment based on clinical assessment was present in 24 out of 70 patients (34.3\%). A lower mean BMI, more previous hospital admissions and more previous eating disorder treatments were associated with diminished mental capacity (Table 2).

Patients' scores on the MacCAT-T are also shown in Table 2. Their mean scores are indicative of good mental capacity. However, the group with diminished mental capacity as assessed by the clinician showed significantly lower appreciation scores on the MacCAT-T. The other three standards did not differ between these two groups. The appreciation score on the MacCAT-T was correlated with the total score on the TAS $(r=-0.35, P=0.005)$, but not with BMI.

There was no difference in the rate of depressive disorder or PTSD between both groups, nor did they differ in EDE score or type of anorexia nervosa (restrictive or binge purge).

\section{Mental capacity and associations with neuropsychological parameters}

The IGT was performed in 60 patients (10 patients did not manage to finish the neuropsychological testing because of concentration difficulties), 20 having diminished mental capacity and 40 having full mental capacity. Overall, a main effect of block was found, $F(4,232)=9.64, P<0.001, \eta_{\mathrm{p}}{ }^{2}=0.14$, showing a learning effect during the task for all participants (Fig. 2). No block $x$ group interaction was found, $F(4,232)=1.56, P=0.20$. The effect of group showed a trend towards significance, $F(1,58)=2.78, P=0.10$, $\eta_{\mathrm{p}}{ }^{2}=0.05$. Further exploration indicated that the group with full mental capacity had a better overall IGT performance (choose more advantageously) than the group with diminished mental capacity.

The groups differed significantly on set-shifting capacity, with the diminished mental capacity group showing poorer set shifting. Central coherence strength showed a trend for the diminished capacity group performing less, indicating more detail focus compared with the group with full mental capacity (Table 2).

None of the neuropsychological parameters (IGT, WCST and RCFT) correlated significantly with the variables BMI or the appreciation subscale of the MacCAT-T.

\section{Discussion}

This is the first study to investigate mental capacity in adults with anorexia nervosa. As shown, diminished mental capacity is a regular feature in patients with this disorder, occurring in a third of patients with severe anorexia nervosa with an average BMI of $15.5 \mathrm{~kg} / \mathrm{m}^{2}$. Although a low BMI is highly relevant, a large proportion (43\%) of 
Table 2 Description of participants and differences between full mental capacity and diminished mental capacity group

\begin{tabular}{|c|c|c|c|c|}
\hline & Total group $(n=70)$ & Full mental capacity ( $n=46)$ & Diminished mental capacity $(n=24)$ & $P$ \\
\hline Age, years: mean (s.d.) & $27.3(9.7)$ & $26.2(9.3)$ & $29.4(10.3)$ & 0.19 \\
\hline Age at onset, years: mean (s.d.) & $17.8(4.9)$ & $17.7(4.6)$ & $18.1(5.7)$ & 0.82 \\
\hline Length of illness, years: mean (s.d.) & $8.6(8.1)$ & $8.5(8.2)$ & $8.9(7.9)$ & 0.84 \\
\hline BMl, mean (s.d.) & $15.5(1.9)$ & $16.1(1.6)$ & $14.2(1.9)$ & $<0.001$ \\
\hline$E D E$, mean (s.d.) & $3.6(1.3)$ & $3.7(1.4)$ & $3.5(1.2)$ & 0.59 \\
\hline ANR $v$. ANP, $\%$ & 49 v. 51 & 47 v. 53 & 55 V. 45 & 0.55 \\
\hline Previous ED treatment, \% & 74 & 65 & 91 & 0.02 \\
\hline Previous hospital admission, \% & 46 & 36 & 65 & 0.02 \\
\hline Medication, \% & 58 & 52 & 68 & 0.22 \\
\hline Relationship, \% & 37 & 43 & 24 & 0.13 \\
\hline Welfare, \% & 25 & 11 & 53 & 0.001 \\
\hline Higher education, \% & 62 & 70 & 45 & 0.06 \\
\hline BDI, mean (s.d.) & $29.9(13.8)$ & $28.8(13.2)$ & $32.1(14.9)$ & 0.35 \\
\hline STAl trait, mean (s.d.) & $59(10.7)$ & $59.3(10.7)$ & $58.4(10.9)$ & 0.73 \\
\hline STAl state, mean (s.d.) & $56.7(12.8)$ & $56.6(12.7)$ & $56.9(13.3)$ & 0.94 \\
\hline TAS, mean (s.d.) & $61.3(9.2)$ & $61.4(9.2)$ & $61.2(9.4)$ & 0.94 \\
\hline MacCAT-T understanding, mean (s.d.) & $5.74(0.40)$ & $5.78(0.36)$ & $5.65(0.48)$ & 0.21 \\
\hline MacCAT-T appreciation, mean (s.d.) & $3.71(0.62)$ & $3.82(0.44)$ & $3.48(0.85)$ & 0.03 \\
\hline MacCAT-T reasoning, mean (s.d.) & $7.29(1.10)$ & $7.39(0.98)$ & $7.11(1.28)$ & 0.32 \\
\hline MacCAT-T choice, mean (s.d.) & $1.94(0.29)$ & $1.96(0.30)$ & $1.91(0.29)$ & 0.58 \\
\hline Depressive disorder, mean (s.d.) & 48.4 & 45.6 & 55.6 & 0.47 \\
\hline PTSD, \% & 23.3 & 23.8 & 22.2 & 0.89 \\
\hline WCST perseverative errors, mean (s.d.) & $7.2(10.3)$ & $5.9(7.9)$ & $10.2(14.4)$ & 0.01 \\
\hline RCFT recall, mean (s.d.) & $18.7(5.9)$ & $19.3(6.3)$ & $17.3(4.7)$ & 0.09 \\
\hline \multicolumn{5}{|c|}{$\begin{array}{l}\text { BMI, body mass index; EDE, Eating Disorder Examination; ANR, anorexia nervosa restrictive type; ANP, anorexia nervosa purging type; ED, eating disorder; BDI, Beck Depression } \\
\text { Inventory; STA, Spielberger Trait State Anxiety Inventory; TAS, Troonto Alexithymia Scale; MacCAT-T, MacArthur Competence Assessment Tool-Treatment; PTSD, post-traumatic stress } \\
\text { disorder; WCST, Wisconsin Card Sorting Test; RCFT, Rey Complex Figure Task. } \\
\text { Significant values in bold. }\end{array}$} \\
\hline
\end{tabular}

patients with a BMI lower than $15 \mathrm{~kg} / \mathrm{m}^{2}$ (in the DSM-5 the cut-off below which the severity of anorexia nervosa is considered to be in the 'extreme' range) did have full mental capacity. Moreover, $17 \%$ of patients with a BMI of $15 \mathrm{~kg} / \mathrm{m}^{2}$ or more showed diminished mental capacity. Therefore, in our opinion, the effects of malnourishment alone cannot explain the relevance of BMI. None of the patients had delirium. Also, by using the MacCAT-T we found

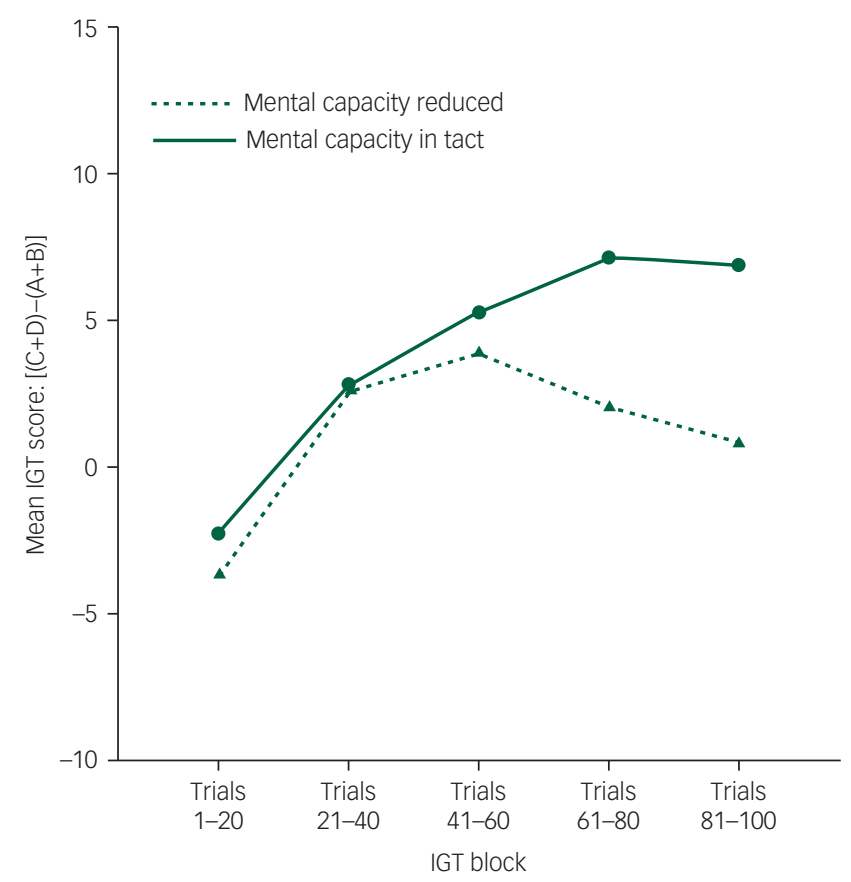

Fig. 2 Mean lowa Gambling Task (IGT) score for two mental capacity groups. that abilities involving higher cognitive functioning (reasoning and understanding) were intact in our sample. This is in line with previous research where neurocognitive impairments in anorexia nervosa appear to be subtle and not directly related to BMI. ${ }^{42}$ In what way BMI influences mental capacity remains as yet unresolved.

Of interest is that by using the MacCAT-T alongside the clinical assessment of mental capacity we demonstrated that it is important to focus on appreciation of illness and treatment. This is in accordance with previous qualitative work done by Tan et al, ${ }^{19,27,43}$ who found that values regarding life and death differ between patients with anorexia nervosa and healthy people, and anorexia nervosa cognitions and behaviour become egosyntonic when severely ill. Also, in a study by Owen et al, ${ }^{44}$ appreciation, rather than reasoning was impaired in psychiatric patients with diminished mental capacity, and reasoning was more impaired in physically ill patients with diminished mental capacity. In previous studies regarding mental capacity to consent to treatment in depression (for a review see Hindmarch $e t \mathrm{al}^{23}$ ), the ability to appreciate is usually found to be diminished, and to a lesser degree understanding and reasoning too. In this review the concept of impaired appreciation is discussed in two ways: on the one hand as an inability to appreciate future possibilities by affective symptoms distorting or blinding the individuals' perception of the future, and on the other hand as an inability to maintain a minimal concern for the self. These features can be seen in patients with anorexia nervosa as well and may be mediated by overattention to detail (commonly found in anorexia ${ }^{41}$ ) and the pathological values mentioned earlier. ${ }^{16}$ As depression rates did not differ between the two mental capacity groups in our study, this suggests that the difference in appreciation must be mediated by an anorexia nervosa-specific factor.

The association of appreciation and a high level of alexithymia $(r=-0.35, P=0.005)$ and the lack of correlation between appreciation and alexithymia with BMI are particularly intriguing. Patients 
often say regarding the consequences of their risky behaviour 'I know, but I don't feel it'. Decision-making has previously been found to be less advantageous when one's current emotional state is a negative one ${ }^{45,46}$ proposed to be caused by a lesser reliance on somatic or affective markers ${ }^{47,48}$ and a tendency to rely stronger on cognitive reasoning. In the present sample all patients had very high depression and anxiety scores, suggesting that diminished mental capacity in this group of severely ill patients may be a result of their negative emotional state and high alexithymia.

Interestingly, results suggest that patients with diminished mental capacity also show impaired decision-making. The IGT assesses the degree to which decisions are guided by somatic markers ('gut feelings'). There was no association of decisionmaking performance with BMI, so the poorer performance of the group with diminished capacity cannot be explained by their significantly lower BMI. This is remarkable, as clinically one would expect severely underweight patients to show impaired decision-making.

The finding that patients with diminished mental capacity show worse set shifting and a trend towards poorer central coherence is intriguing in the light of decision-making processes. Although a relationship between these two neuropsychological abilities and decision-making has not been shown so far, it is tempting to presume an association. A rigid thinking style proposedly hampers decision-making by not being able to change problem-solving strategy or seeing the bigger picture.

Summarising these findings, it appears that several factors contribute to diminished mental capacity. Low BMI seems an important factor, suggesting that clinicians need to be alert to mental capacity issues in these patients. Treatment history and poor societal functioning can also point towards diminished mental capacity. The way in which poor societal functioning is related to diminished mental capacity remains uncertain. There may be underlying factors contributing to both diminished mental capacity to consent to treatment and poor societal functioning. Alternatively we cannot exclude the possibility that the clinician might also be influenced in their clinical judgement by the poor societal functioning. More subtle contributing factors are the inability to change strategies, the slight focus on detail and the combination of negative emotional states. Together with diminished mentalisation these subtle factors might lead to inadvantageous decision-making on a neuropsychological level and decreased appreciation of the illness and treatment and therefore diminished mental capacity.

\section{Strengths and limitations}

Strengths of the study are the relatively large number of patients, the severe psychopathology of the group (as this is the group mental capacity issues are relevant for in clinical practice) and the wide range of assessment measures, including a structured clinical interview (SCID-I). Also the combination with neuropsychological parameters regarding decision-making is highly innovative and only previously examined in a study in patients with schizophrenia. ${ }^{49}$ A limitation is the subjectivity of the clinical assessment of mental capacity and possibly prejudiced mental capacity judgement by the psychiatrist on seeing a very underweight patient ('being so underweight, she must lack capacity'). As the clinical judgement is inherently subjective we aimed to minimise this limitation by involving psychiatrists highly specialised in eating disorders, used to working with severely ill patients with anorexia nervosa. The finding that $43 \%$ of patients with anorexia with a BMI lower than $15 \mathrm{~kg} / \mathrm{m}^{2}$ was judged to have full mental capacity speaks against prejudiced judgement by the psychiatrists.

\section{Implications for clinical practice}

When faced with the task to assess mental capacity in patients with anorexia nervosa, clinicians need to bear in mind that a low BMI is certainly informative, but not exclusively so. All too often mental capacity is said to be adequate because the patient understands their situation. Our results show that although understanding may be adequate, it is the appreciation that is more important in the mental capacity assessments in anorexia nervosa. We urge clinicians not to be mistaken in the idea that a low BMI means lacking mental capacity. In clinical practice we therefore advise the use of the so-called static markers such as BMI and history together with more dynamic markers as societal functioning, the emotional state of the patient, the mentalisation ability and the degree of appreciation of illness and treatment. This calls for careful consideration of these factors by the clinician. As far as treatment is concerned, these findings support the importance of incorporating modules to enhance emotion regulation and ameliorate neuropsychological deficiencies. Identifying emotions, recognising them and learning how to deal with emotions may not only benefit patients because of a higher chance of recovery, but it might also improve their decisionmaking abilities and thereby their mental capacity. Interventions such as cognitive remediation therapy, ${ }^{50,51}$ focusing on set-shifting difficulties, can be useful to strengthen the neuropsychological functions presumably important in enabling patients to change rigidly set behaviour.

In future research it would be important to have follow-up studies to assess the relevance of mental capacity problems on the course of treatment. Do patients with diminished mental capacity do worse? Also in what way mental capacity can be improved would be a relevant line of research. Does it improve with a higher BMI, as would be expected from this study? Or are other factors more important in improving mental capacity? Also studies performed under more stressful conditions could be relevant, for example in emergency situations. We presume mental capacity would be less in stressful circumstances, but no research has been conducted yet. If this were true, clinicians working in emergency departments would have to be even more alert before discharging patients with severe anorexia nervosa because they seem to 'understand' their dire situation.

\footnotetext{
Isis F.F.M. Elzakkers, MD, MSC, Unna N. Danner, PhD, Altrecht Eating Disorders Rintveld, Altrecht Mental Health Institute, Zeist, The Netherlands; Hans W. Hoek, MD, $\mathrm{PhD}$, Altrecht Eating Disorders Rintveld, Altrecht Mental Health Institute, Zeist, The Netherlands; Parnassia Bavo Psychiatric Institute, The Hague, The Netherlands; Department of Psychiatry, University Medical Center Groningen, Groningen, The Netherlands; Department of Epidemiology, Mailman School of Public Health, Columbia University, New York, USA; Annemarie A. van Elburg, MD, PhD, Altrecht Eating Disorders Rintveld, Altrecht Mental Health Institute, Zeist, The Netherlands; Department of Social Sciences, Utrecht University, Utrecht, The Netherlands

Correspondence: Isis F.F.M. Elzakkers, MD, Altrecht Eating Disorders Rintveld, Altrecht Mental Health Institute, Wenshoek 4, 3705 WE, Zeist, The Netherlands. Email: i.elzakkers@altrecht.nl

First received 25 Nov 2015, final revision 3 Feb 2016, accepted 11 Feb 2016
}

\section{Funding}

This research was supported by a grant from the Nuts Ohra Foundation.

\section{Acknowledgements}

The authors would like to thank Professor Ulrike Schmidt and Dr Lot Sternheim for commenting on the paper. 


\section{Appendix}

\section{Case vignette 1}

A 21-year-old woman with anorexia nervosa for 3 years with a BMI of $13.4 \mathrm{~kg} / \mathrm{m} 2$, bradycardia and hypothermia. Her parents divorced when she was 3 years old and she and her sisters were raised by a mother with schizophrenia, who included her children in her hallucinations and delusions. In the last few years of increasing social isolation, she gave up her university education and became increasingly anxious. In the first meeting with the clinician she did not speak much, and when she did it was in short sentences and very softly. She could not explain her behaviour, provided no arguments for the restricted eating and could also not reflect on past choices (e.g. study choice) nor on future wishes in life. According to a friend the patient displayed a very high degree of ambivalence in all areas of life and came to decisions only after long periods of doubt. The patient denied the low societal functioning and also the need for treatment, but she accepted the advice to be admitted.

\section{Case vignette 1}

A 48-year-old woman, with anorexia nervosa for 23 years, a BMI of $15.6 \mathrm{~kg} / \mathrm{m}^{2}$ and comorbid post-traumatic stress disorder (physical and sexual abuse), misuse of alcohol, social phobia and a borderline personality disorder. Her societal functioning was low. She was seeking treatment after deterioration of her eating disorder and body weight after a period of gastrointestinal problems. Although she acknowledged the need for treatment, her reflection on the severity of her present condition and the areas of importance to address in the treatment (such as emotion regulation) was low. Also, the clinician felt that her expectations of the treatment were inappropriately high which made the impression that she did not genuinely grasp the pervasiveness of her condition. She accepted the advice for in-patient treatment.

\section{References}

1 Hoek HW. Incidence, prevalence and mortality of anorexia nervosa and othe eating disorders. Curr Opin Psychiatry 2006; 19: 389-94.

2 Arcelus J, Mitchell AJ, Wales J, Nielsen S. Mortality rates in patients with anorexia nervosa and other eating disorders: a meta-analysis of 36 studies. Arch Gen Psychiatry 2011; 68: 724-31.

3 Keel PK, Brown TA. Update on course and outcome in eating disorders. Int J Eat Disord 2010; 43: 195-204.

4 Smink FR. Epidemiology of eating disorders: incidence, prevalence and mortality rates. Curr Psychiatry Rep 2012; 14: 406-14.

5 Strober $M$, Freeman R, Morrell W. The long-term course of severe anorexia nervosa in adolescents: survival analysis of recovery, relapse, and outcome predictors over 10? 15 years in a prospective study. Int J Eat Disord 1997; 22: 339-60

6 Treasure J, Claudino AM, Zucker N. Eating disorders. Lancet 2010; 375: 583-93.

7 Zipfel S, Giel KE, Bulik CM, Hay P, Schmidt U. Anorexia nervosa: aetiology, assessment and treatment. Lancet Psychiatry 2015; 2: 1099-111.

8 Kaye WH, Wierenga CE, Bailer UF, Simmons AN, Bischoff-Grethe A. Nothing tastes as good as skinny feels: the neurobiology of anorexia nervosa. Trends Neurosci 2013; 36: 110-20.

9 Walsh BT. The enigmatic persistence of anorexia nervosa. Am J Psychiatry 2013; 170: $477-84$

10 Lopez C, Tchanturia K, Stahl D, Treasure J. Central coherence in eating disorders: a systematic review. Psychol Med 2008; 38: 1393-404.

11 Tchanturia K, Davies $H$, Roberts $M$, Harrison A, Nakazato $M$, Schmidt $U$, et al. Poor cognitive flexibility in eating disorders: examining the evidence using the Wisconsin Card Sorting Task. PLoS One 2012; 7: e28331.

12 Tchanturia K, Liao PC, Uher R, Lawrence N, Treasure J, Campbell IC. An investigation of decision making in anorexia nervosa using the lowa Gambling Task and skin conductance measurements. I Int Neuropsychol Soc 2007; 13 635-41.
13 Danner UN, Sanders N, Smeets PAM, van Meer F, Adan RAH, Hoek HW, et al. Neuropsychological weaknesses in anorexia nervosa: set-shifting, central coherence, and decision making in currently ill and recovered women. Int J Eat Disord 2012; 45: 685-94.

14 Galimberti E, Fadda E, Cavallini MC, Martoni RM, Erzegovesi S, Bellodi L. Executive functioning in anorexia nervosa patients and their unaffected relatives. Psychiatry Res 2013; 208: 238-44.

15 Chan TWS, Ahn W-Y, Bates JE, Busemeyer JR, Guillaume S, Redgrave GW, et al. Differential impairments underlying decision making in anorexia nervosa and bulimia nervosa: a cognitive modeling analysis. Int J Eat Disord 2014; 47: 157-67.

16 Tan JOA, Hope T, Stewart A. Anorexia nervosa and personal identity: the accounts of patients and their parents. Int J Law Psychiatry 2003; 26: 533-48.

17 Grisso T, Appelbaum PS. Assessing Competence to Consent to Treatment: A Guide for Physicians and Other Health Professionals. Oxford University Press, 1998.

18 Okai D, Owen G, McGuire H, Singh S, Churchill R, Hotopf M. Mental capacity in psychiatric patients: systematic review. Br J Psychiatry 2007; 191: 291-7.

19 Tan J, Hope T, Stewart A. Competence to refuse treatment in anorexia nervosa. Int J Law Psychiatry 2003; 26: 697-707.

20 Turrell SL, Peterson-Badali M, Katzman DK. Consent to treatment in adolescents with anorexia nervosa. Int J Eat Disord 2011; 44: 703-7.

21 Breden TM, Vollmann J. The cognitive based approach of capacity assessment in psychiatry: a philosophical critique of the MacCAT-T. Health Care Anal 2004; 12: 273-83; discussion 265-72.

22 Owen GS, Freyenhagen F, Richardson G, Hotopf M. Mental capacity and decisional autonomy: an interdisciplinary challenge. Inquiry 2009; 52: 79-107.

23 Hindmarch T, Hotopf M, Owen G. Depression and decision-making capacity for treatment or research: a systematic review. BMC Med Ethics 2013; 14: 54.

24 Vollmann J. "But I don't feel it”. values and emotions in the assessment of competence in patients with anorexia nervosa. Philos Psychiatr Psychol 2006; 13: 289-91.

25 Charland LC. Anorexia and the MacCAT-T test for mental competence, validity, value, and emotion. Philos Psychiatr Psychol 2007; 13: 283-7.

26 Tan J, Stewart A, Hope T. Decision-making as a broader concept. Philos Psychiatr Psychol 2009; 16: 345-9.

27 Tan J, Hope T, Stewart A, Fitzpatrick R. Control and compulsory treatment in anorexia nervosa: the views of patients and parents. Int J Law Psychiatry 2003; 26 $627-45$

28 Grisso T, Appelbaum PS. Appreciating anorexia: decisional capacity and the role of values. Philos Psychiatr Psychol 2006; 13: 293-301.

29 American Psychiatric Association. Diagnostic and Statistical Manual of Mental Disorders (Fourth Edition, Test Revision) (DSM-IV-TR). APA, 2000.

30 Cooper $Z$, Fairburn C. The eating disorder examination: a semi-structured interview for the assessment of the specific psychopathology of eating disorders. Int J Eat Disord 1987; 6: 1-8.

31 Grisso T, Appelbaum PS, Hill-Fotouhi C. The MacCAT-T: a clinical tool to assess patients' capacities to make treatment decisions. Psychiatr Serv 1997; 48: 1415-9.

32 First MB, Spitzer RL, Gibbon $M$, Williams JBW. Structured Clinical Interview for DSM-IV-TR Axis I Disorders. American Psychiatric Press, 1996.

33 Beck AT, Steer RA, Brouwn GK. Manual for the Beck Depression Inventory-II. Psychological Corporation, 1996.

34 Spielberger CD, Gorsuch RL, Lushene R, Vagg PR, Jacobs GA. Manual for the State-Trait Anxiety Inventory. Consulting Psychologists Press, 1983.

35 Bagby RM, Parker JDA, Taylor GJ. The twenty-item Toronto Alexithymia scale-Item selection and cross-validation of the factor structure. J Psychosom Res 1994; 38: 23-32.

36 Bagby RM, Taylor GJ, Parker JDA. The twenty-item Toronto Alexithymia scale-II. Convergent, discriminant, and concurrent validity. J Psychosom Res 1994; 38 33-40.

37 Bechara A, Damasio AR, Damasio $H$, Anderson SW. Insensitivity to future consequences following damage to human prefrontal cortex. Cognition 1994; 50. $7-15$

38 Osterrieth PA. Le test de copie d'une figure complexe: contribution àl'é tude de la perception et de la mémoire [The complex figure test: it's contribution in the study of perception and memory]. Delachaux \& Niestlé, 1944.

39 Berg EA. A simple objective technique for measuring flexibility in thinking. J Gen Psychol 1948; 39: 15-22.

40 Stedal K, Frampton I, Landrø NI, Lask B. An examination of the Ravello profile? A neuropsychological test battery for anorexia nervosa. Eur Eat Disord Rev 2012; 20: $175-81$. 
41 Lang K, Lopez C, Stahl D, Tchanturia K, Treasure J. Central coherence in eating disorders: an updated systematic review and meta-analysis. World J Biol Psychiatry 2014; 15: 586-98.

42 Fowler L, Blackwell A, Jaffa A, Palmer R, Robbins TW, Sahakian BJ, et al. Profile of neurocognitive impairments associated with female in-patients with anorexia nervosa. Psychol Med 2006; 36: 517-27.

43 Tan JO, Stewart A, Fitzpatrick R, Hope T. Attitudes of patients with anorexia nervosa to compulsory treatment and coercion. Int J Law Psychiatry 2010; 33: 13-9.

44 Owen GS, Szmukler G, Richardson G, David AS, Raymont V, Freyenhagen F, et al. Decision-making capacity for treatment in psychiatric and medical in-patients: cross-sectional, comparative study. Br J Psychiatry 2013; 203: 461-7.

45 Suhr JA, Tsanadis J. Affect and personality correlates of the lowa gambling task. Pers Indiv Differ 2007; 43: 27-36.

46 de Vries M, Holland RW, Witteman CLM. In the winning mood: affect in the lowa gambling task. Judge Decis Mak 2008; 3: 42-50.
47 Damasio AR. Descartes' error and the future of human life. SCi Am 1994; 271: 144 .

48 Bechara A, Damasio H, Damasio AR. Emotion, decision making and the orbitofrontal cortex. Cereb Cortex 2000; 10: 295-307.

49 Stroup TS, Appelbaum PS, Gu H, Hays S, Swartz MS, Keefe RSE, et al. Longitudinal consent-related abilities among research participants with schizophrenia: results from the CATIE study. Schizophr Res 2011; 130: 47-52.

50 Tchanturia K, Lock J. Cognitive remediation therapy for eating disorders: development, refinement and future directions. Curr Top Behav Neurosci 2011; 6: 269-87.

51 Danner UN, Dingemans $A E$, Steinglass J. Cognitive remediation therapy for eating disorders. Curr Opin Psychiatry 2015; 28: 468-72. 